\title{
Effect of new crystalline phase on the ionic conduction properties of sodium perchlorate salt doped carboxymethyl cellulose biopolymer electrolyte films
}

\author{
Supriya K Shetty ${ }^{1,2} \cdot \mid$ Ismayil $^{2}$ (I) $\cdot$ I. M. Noor ${ }^{3}$
}

Received: 29 July 2021 / Accepted: 30 September 2021 / Published online: 8 October 2021

(c) The Author(s) 2021

\begin{abstract}
Dopant induced modifications in the microstructure of sodium carboxymethyl cellulose (NaCMC) were characterized by FTIR, XRD, DSC and EIS techniques. FTIR analysis exhibited a considerable microstructural modification in NaCMC upon $\mathrm{NaClO}_{4} \cdot \mathrm{H}_{2} \mathrm{O}$ doping invoked through complex formation via Lewis acid-base interaction and hydrogen bond formation between ions and dipoles. This resulted in the modification in the orderliness/disorderliness of polymer chains as observed from XRD deconvolution. At higher salt concentrations, the complexity of the network causes the formation of new amorphous and crystalline phases as reflected in the XRD studies. DSC analysis showed an increase in $\mathrm{T}_{\mathrm{g}}$ as the salt concentration increased, indicating a reduction in polymer chains flexibility. The contribution of free ions has masked over the enhancement in amorphous content to conductivity at a lower concentration of salt in the matrix, later on, the formation of a new crystalline phase due to transient crosslinks by $\mathrm{Na}^{+\cdots} \mathrm{ClO}_{4}{ }^{-\cdots} \mathrm{Na}^{+}$has affected the ion transport process.
\end{abstract}

Keywords Carboxymethyl cellulose $\cdot$ Sodium perchlorate $\cdot$ Ionic conductivity $\cdot$ Transient crosslinks $\cdot$ Solid polymer electrolyte

\section{Introduction}

Rechargeable sodium-ion batteries (SIBs) based on solid polymer electrolytes (SPE) are considered to be one of the promising candidates for next-generation large-scale highenergy and high-safety energy storage applications owing to the availability of sodium resources $[1,2]$. SPEs are a fabulous candidate as an electrolyte due to low cost, ease of preparation, high flexibility, lightweight, exhibits good compatibility with the electrode and can bear the volume change at the electrode/electrolyte interface during the charge/discharge process due to excellent mechanical strength. An SPE

Ismayil

ismayil.mit@manipal.edu; ismayil.486@gmail.com

1 Department of Sciences, Manipal Academy of Higher Education, 576104 Manipal, Karnataka, India

2 Department of Physics, Manipal Institute of Technology, Manipal Academy of Higher Education, 576104 Manipal, Karnataka, India

3 Physics Division, Centre of Foundation Studies for Agricultural Science, Universiti Putra Malaysia, 43400 UPM Serdang, Selangor, Malaysia must have main properties such as high Ionic conductivity $\left(\geq 10^{-3} \mathrm{Scm}^{-1}\right)$ at operating temperature range, cation transference number $\left(t_{i o n} \approx 1\right)$, a wide electrochemical window, excellent thermal and electrochemical stability, sufficient mechanical strength to suppress dendrite growth (in case of metal anodes) and to withstand the stress generated during the charge/discharge cycle with flexibility, environmentally friendly, simple and low-cost processing [3]. Achieving desirable bulk ionic conductivity with a wide electrochemical stability window that has sufficient mechanical strength is still a challenging aspect in the case of solid polymer electrolytes [4]. The above-mentioned properties not only depend on the polymer host material architecture but also on the Na-salt doped, and therefore it is necessary to have a fundamental understanding of the electrolyte design to optimize the desirable properties of a solid-electrolyte [5]. Polysaccharides-containing natural biopolymers such as cellulose, chitin, starch, carrageenan and their derivatives have emerged as a host polymer for solid electrolyte application in the creation of a new energy storage system due to its abundancy, biocompatibility, low cost and environmentally friendly nature [6]. 
In this study, anionic polysaccharides, sodium carboxymethyl cellulose (NaCMC) was selected as the host polymer as it is a highly abundant low-cost natural polymer with the good film-forming ability and high mechanical strength. $\mathrm{NaCMC}$ is a semi-synthetic derivative of cellulose, and the presence of sodium carboxymethyl group $\left(\mathrm{CH}_{2} \mathrm{COONa}\right)$ makes it highly soluble in water and also act as a polyelectrolyte [7]. NaCMC also has emerged as a promising inexpensive alternative binder for the active electrode material particles over conventional high cost, non-environmentally friendly binder, polyvinylidene difluoride (PVDF) for lithium-ion and sodium-ion batteries with improved performance [8-10]. While selecting a polymer as a matrix, it should satisfy specific criteria; it should be amorphous in nature with high solvation power with coordination sites to assist ion-pair dissociation. The degree of dissociation of the salt plays a vital role in the ion transport mechanism that depends on the local dielectric properties of the polymer host; associated with the number of coordination sites and functionality in the polymer structure [11]. The presence of hydroxy, carbonyl and the ether group in the glycosidic linkage and pyranose ring, offers a large number of coordination sites for ions. The existence of a very low crystalline phase makes NaCMC a suitable candidate as a polymer host. The electrolyte properties depend on the microstructural modification brought about by salt-polymer complex formation. Therefore, a better understanding of, how the dopant induced modification plays a significant role in the electrolyte is necessary.

In our previous work, SPE of NaCMC doped with sodium nitrate $\left(\mathrm{NaNO}_{3}\right)$ was analyzed and the polymer-salt complex formation has enhanced the amorphous phase resulted in enhancement in ionic conductivity [12]. In the present work, $\mathrm{NaCMC}$ has been doped with sodium perchlorate monohydrate $\left(\mathrm{NaClO}_{4} \cdot \mathrm{H}_{2} \mathrm{O}\right)$ to investigate the impact of molecular complexation via ion-dipole interaction and transient crosslinks on the microstructural properties. The understanding of the conduction mechanism in SPEs is a complicated process, due to its dependency on many factors such as the degree of crystallinity, charge carrier concentration, segmental mobility of polymer chains, interaction of ions (while conducting) and size of ions. Even though ionic conductivity is mainly focused on the amorphous content in the polymer matrix, in this study, a new result has been achieved unique from previous work.

\section{Experimental}

\section{Electrolyte preparation}

Sodium carboxymethyl cellulose (High viscosity 1100$1900 \mathrm{cPs}$ ) was purchased from SD fine chemicals Pvt.
Ltd., Mumbai, India and sodium perchlorate monohydrate $\left(\mathrm{NaClO}_{4} \cdot \mathrm{H}_{2} \mathrm{O}\right)$ was procured from Loba Chemie Pvt. Ltd., India. Solid polymer electrolyte films of $\mathrm{NaCMC}-\mathrm{NaClO}_{4}$. $\mathrm{H}_{2} \mathrm{O}$ were prepared by dissolving different weight percentages of NaCMC and sodium perchlorate monohydrate in $100 \mathrm{~mL}$ of double-distilled water. The mixture was subjected to continuous stirring for about $4 \mathrm{~h}$. at $40{ }^{\circ} \mathrm{C}$ until homogeneity was achieved and then casted on glass Petri dishes and allowed for drying for a few days at room temperature before further drying in the desiccator to remove moisture content. The free-standing films were obtained by peeling off from the dish and kept in a vacuum desiccator for further characterization. The compositions of samples and their designation are tabulated in Table 1.

\section{Solid polymer electrolyte characterization}

FTIR spectra were obtained by using IRPrestige-21 FTIR SHIMADZU to confirm the complex formation in the SPE system. Diamond crystal is used in ATR accessory. The sample was placed in front of a diamond crystal and IRradiation was passed through it. The spectra were recorded in the transmittance mode in the wavenumber range between 400 and $4000 \mathrm{~cm}^{-1}$ with the resolution of $4 \mathrm{~cm}^{-1}$. A 3rd generation Empyrean, Malvern Panalytical diffractometer was used to record the X-ray diffraction pattern from $2 \theta$ angle of $5^{\circ}$ to $90^{\circ}$ with X-ray source: $\mathrm{Cu}-\mathrm{K}_{\alpha}$ radiation of wavelength (1.5406 $\AA$ ), to study the interaction of salt in the crystalline/ amorphous or both regions of polymer. To investigate the thermal behaviour of the SPE system, SHIMADZU DSC-60 PLUS MODEL was used to record the DSC thermograph at a heating scan rate of $10{ }^{\circ} \mathrm{C} \mathrm{min}{ }^{-1}$ under a nitrogen flow rate of $40 \mathrm{~mL} \mathrm{~min}^{-1}$ in the temperature range between 30 and $350{ }^{\circ} \mathrm{C}$. Electrical impedance spectroscopy (EIS) was carried out at room temperature $\left(27^{\circ} \mathrm{C}\right)$ using Agilent $4294 \mathrm{~A}$ Precision Impedance Analyzer in the frequency range of $40 \mathrm{~Hz}$ to $5 \mathrm{MHz}$ to determine the electrical properties of electrolyte prepared. An ac signal of $500 \mathrm{mV}$ was applied across the SPE, sandwiched between the silver electrode of

Table 1 Composition of the samples and their designation

\begin{tabular}{lll}
\hline Composition $\left(\mathrm{NaCMC}+\mathrm{NaClO}_{4} \cdot \mathrm{H}_{2} \mathrm{O}\right)$ & Designation \\
$\mathrm{NaCMC}(\mathrm{g})$ & $\mathbf{N a C l O 4} \cdot \mathbf{H 2 O}(\mathrm{g})$ & \\
\hline 2 & 0 & $\mathrm{CP} 0$ \\
1.9 & 0.1 & $\mathrm{CP} 5$ \\
1.8 & 0.2 & $\mathrm{CP} 10$ \\
1.7 & 0.3 & $\mathrm{CP} 15$ \\
1.6 & 0.4 & $\mathrm{CP} 20$ \\
1.5 & 0.5 & $\mathrm{CP} 25$ \\
1.4 & 0.6 & $\mathrm{CP} 30$ \\
\hline
\end{tabular}


$0.25 \mathrm{~cm}^{2}$ area. The mechanical characteristics of SPEs in a rectangular shape of gauge length $50 \mathrm{~mm}$ and width of $25 \mathrm{~mm}$ were evaluated at room temperature according to ASTM D882 standards using a universal testing machine (UTM), Dak System Inc. 7200 series, at a crosshead speed of $0.1 \mathrm{~mm} \mathrm{~min} \mathrm{~m}^{-1}$.

\section{Results and discussion}

\section{ATR-FTIR analysis}

FTIR spectra for $\mathrm{NaCMC}, \mathrm{NaClO}_{4} \cdot \mathrm{H}_{2} \mathrm{O}$ and $\mathrm{NaCMC}$ : $\mathrm{NaClO}_{4} \cdot \mathrm{H}_{2} \mathrm{O}$ SPEs films from the wavenumber region between 4000 and $500 \mathrm{~cm}^{-1}$ are presented in Fig. 1. Prominent bands are observed in the wavenumber region from 3700 to $3000 \mathrm{~cm}^{-1}$ corresponding to symmetric stretching of the $-\mathrm{OH}$ group. The $-\mathrm{CH}$ symmetric stretching shows a vibrational peak at $2924 \mathrm{~cm}^{-1}$. Asymmetric stretching of carboxylate group $\left(\mathrm{COO}^{-}\right)$is responsible for the sharp and strong absorption peak at $1584 \mathrm{~cm}^{-1}$. The vibrational bands corresponding to $-\mathrm{CH}_{2}$ scissoring and $-\mathrm{OH}$ bending are located at $1409 \mathrm{~cm}^{-1}$ and $1327 \mathrm{~cm}^{-1}$, respectively. The band at $1053 \mathrm{~cm}^{-1}$ ascribed to $\mathrm{C}-\mathrm{O}-\mathrm{C}$ stretching [13, 14]. The addition of salt has resulted in a slight shift in the band corresponding to $-\mathrm{C}-\mathrm{O}-\mathrm{C}$ to the high wavenumber region as well as shape of the band due to Lewis acid-base interaction between Lewis base oxygen and $\mathrm{Na}^{+}$cation (a quite strong Lewis acid). A prominent band shift of $-\mathrm{OH}$ and $-\mathrm{CH}$ stretching group is due to the formation of a

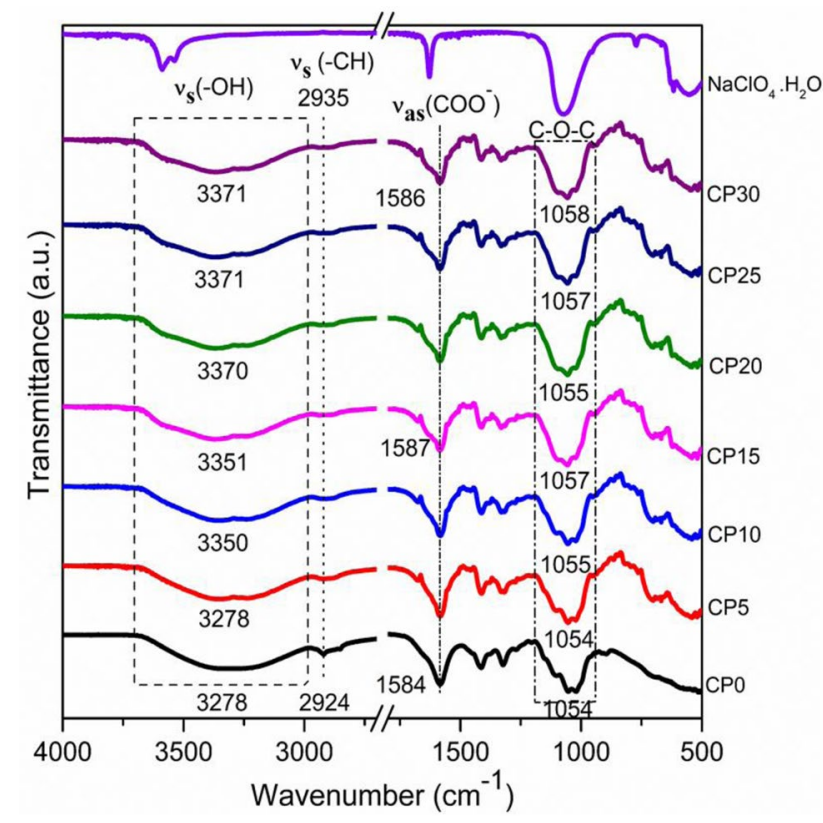

Fig. 1 FTIR spectra of $\mathrm{NaCMC} \mathrm{NaClO}_{4} \cdot \mathrm{H}_{2} \mathrm{O}$ and $\mathrm{NaClO}_{4} \cdot \mathrm{H}_{2} \mathrm{O}$ doped NaCMC solid polymer electrolyte hydrogen bond between the hydrogen atom of hydroxyl functional group and methylene group of $\mathrm{NaCMC}$ with the oxygen of $\mathrm{ClO}_{4}^{-}$, with no shift in the band corresponding to $-\mathrm{CH}_{2}$ scissoring and $-\mathrm{OH}$ bending. Free perchlorate anion is of tetrahedral symmetry $\left(T_{d}\right)$ exhibiting four fundamental modes of vibrations $\left(A_{1}+E+2 F_{2}\right)$, in which the strongest perchlorate peak at $1074 \mathrm{~cm}^{-1}$ corresponds to asymmetric stretching mode. A noticeable change in the pattern of the bands was observed in the wavenumber region between 1200 and $900 \mathrm{~cm}^{-1}$ corresponding to the ether stretching mode [15], due to the fall of the perchlorate peak in this region. Figure 2, schematically represents the interaction between $\mathrm{NaCMC}$ with $\mathrm{ClO}_{4}^{-} \& \mathrm{Na}^{+}$ions after doping.

FTIR Deconvolution for all samples has been carried out in the wavenumber region of 1200 and $900 \mathrm{~cm}^{-1}$ as shown in Fig. 3 to investigate the overlapping of the $\mathrm{ClO}_{4}^{-}$ and $-\mathrm{C}-\mathrm{O}-\mathrm{C}$ bands using non-linear fitting software. The absorbance peaks were fitted by the Gaussian function after baseline correction and the total area of the deconvoluted bands were estimated. The deconvoluted spectra of NaCMC consist of 5 bands (as shown in Fig. 3 centred at $1156,1102,1052,1022$ and $1000 \mathrm{~cm}^{-1}$ which corresponds to skeletal vibration of $\mathrm{C}-\mathrm{O}$ of the glycosidic bridge, $\mathrm{C}-\mathrm{C}$ bonds and deformational vibrations of the $\mathrm{CCH}, \mathrm{COH}$ and HCO bonds, respectively [16]. A band at $1155 \mathrm{~cm}^{-1}$ is assigned predominately to a ring-vibrational mode corresponding to $-\mathrm{CO}$ and $-\mathrm{CC}$ stretching with $-\mathrm{COH},-\mathrm{CCH}$ bending $[17,18]$. The band observed at $1102 \mathrm{~cm}^{-1}$ is attributed to $\mathrm{C}(5)-\mathrm{C}(6)$ and $\mathrm{C}(6)-\mathrm{O}(6)$ stretching vibrations. $\mathrm{A}-\mathrm{COC}$ bending and $\mathrm{C}(6) \mathrm{O}$ bending are assigned to bands at $1052 \mathrm{~cm}^{-1}$ and $1022 \mathrm{~cm}^{-1}$ respectively. The area under the deconvoluted IR absorption peak against salt concentration is shown in Fig. 4. The areas are given as percentages with respect to the area under the parent peak (CP0). An increase in the area indicates the occurrence of dissociation of the ions (up to CP20) followed by saturation at higher dopant concentration indicates either the formation of ion-aggregates or saturation in salt-polymer complexation that has occurred due to non-availability of functional group (especially ether group) to dissociate the salt and will be discussed in the coming section. From the FTIR study, it is clear that interaction between the salt and the polymer has led to complex formation via intermolecular hydrogen bonding and Lewis acid-base interaction, and these two effects would result in the promotion of free ions due to the presence of polar group $-\mathrm{O}-,-\mathrm{H}-$ and $-\mathrm{C}-\mathrm{H}-$, in the polymer chain that helps to dissociate the salt [19]. A noticeable change is brought about by hydrogen bonding for higher salt concentration rather than Lewis-acid base interaction, indicating the hydrogen bonding is strong enough to cause a prominent change in the IR spectra. 
Fig. 2 Possible interaction of perchlorate anion and $\mathrm{Na}^{+}$ cation with functional group of the polymer

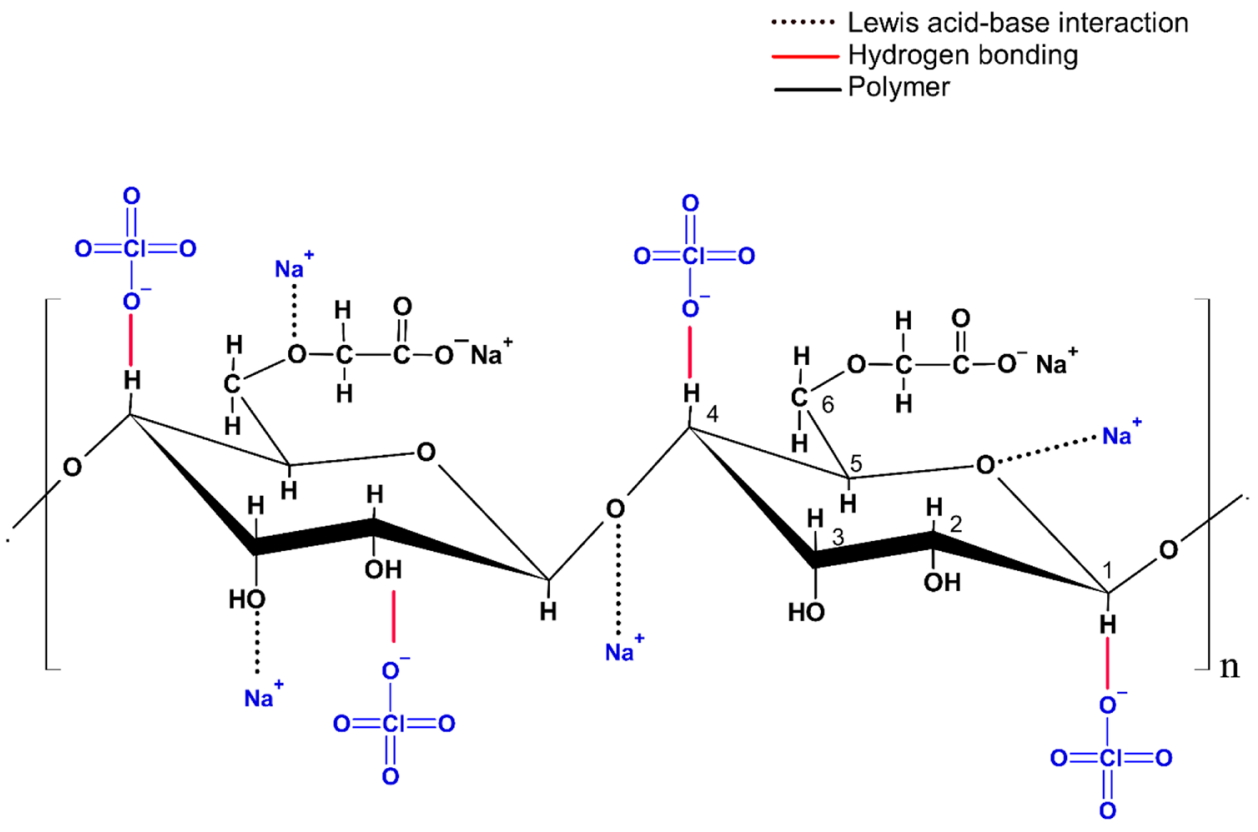

\section{XRD analysis}

The change in the microstructure of polymer upon addition of $\mathrm{NaClO}_{4} \cdot \mathrm{H}_{2} \mathrm{O}$ salt was investigated through a Wide-angle $\mathrm{X}$-ray diffractogram. XRD reflected the change in crystalline structure and degree of crystallinity of the electrolytes. From Fig. 5, it can be seen that pure $\mathrm{NaCMC} \mathrm{(CP0} \mathrm{sample)} \mathrm{exhib-}$ ited two broad peaks centred at $2 \theta$ angles at $13^{\circ}$ and $21^{\circ}$, corresponding to the crystallographic plane of (110) and (200), respectively [20]. Progressively disappearance of the peak at a lower angle indicates the destruction of the crystalline structure of $\mathrm{NaCMC}$ after doping with $\mathrm{NaClO}_{4} \cdot \mathrm{H}_{2} \mathrm{O}$ salt. $\mathrm{NaCMC}$ peak at $21^{\circ}$ is observed to shift towards higher diffraction angle which confirms the formation of complexation. XRD pattern of $\mathrm{NaClO}_{4} \cdot \mathrm{H}_{2} \mathrm{O}$ exhibits crystalline peaks at $2 \theta=17.3^{\circ}$, $18.14^{\circ}, 20.22^{\circ}, 22.13^{\circ}, 24.5^{\circ}, 32.91^{\circ}, 36.91^{\circ}, 50.06^{\circ}, 53.04^{\circ}$, $54.03^{\circ}, 58.21^{\circ}, 69.34^{\circ}, 78.57^{\circ}, 87.12^{\circ}$ and $88.52^{\circ}$. These peaks are absent in the polymer-salt complexes indicating the salt has completely complexed within the polymer host matrix. However, for NaCMC consisting of $25 \mathrm{wt} \%$ salts, the crystalline peaks are observed at $2 \theta$ angle of $49.60^{\circ}, 49.84^{\circ}, 63.96^{\circ}$ and $81.48^{\circ}$ while the sample of $70 \mathrm{wt} \%$ NaCMC-30 wt $\%$ $\mathrm{NaClO}_{4}$ shows the crystalline peaks at $2 \theta$ of $50.36^{\circ}, 64.08^{\circ}$ and $81.45^{\circ}$. The peak positions seem to be slightly shifted with respect to the original peaks of the dopant, confirmed the formation of the new crystalline phase. Thus, structural rearrangement brought about in polymer upon doping that in turn, affects the molecular dynamics and is reflected in XRD pattern. It is a well-established fact that crystalline and amorphous phase coexists in most polymeric materials. To separate crystalline peaks from the continuous scattering background, XRD deconvolution has been carried out. The deconvolution of the XRD pattern was performed using Fityk 1.3.1 software considering the Gaussian function. Equation 1 was used to evaluate the percentage of crystallinity, $\chi_{c}$ for each sample [21].

${ }_{c}=\frac{A_{c}}{A_{c+} A_{a}} \times 100 \%$

Here $A_{c}$ is the area of the peak corresponding to crystalline region, $A_{a}$ is the area of the peak corresponding to the amorphous region. The evaluated values are tabulated in Table 2.

Figure 6 demonstrates the XRD deconvoluted pattern of the SPEs system. As per the pattern, the intensity of the crystalline peaks corresponding to the (110) plane decreases, thus enhance the amorphous character of the electrolyte. This results in a reduction in the percentage of crystallinity as observed in Table 2. Sample CP15 exhibited the lowest percentage of crystallinity of $10.07 \%$. A slight increase in crystallinity has been observed for samples with more than $15 \mathrm{wt} \%$ of salt in $\mathrm{NaCMC}$ due to the formation of a new crystalline phase which then overwhelmed the formation of the new amorphous phase. From the XRD, it can be concluded that the dopant interacts with polymer mainly via hydrogen bonding for higher dopant concentration as observed from the FTIR deconvolution causing local ordering/disordering of the polymer-salt complexed structure.

\section{Differential Scanning Calorimetry (DSC) analysis}

The thermal properties that define the physical state of polymer electrolytes i.e. glass transition temperature $\left(T_{g}\right)$, have been measured using DSC technique. Figure 7 shows the DSC thermogram for NaCMC-based solid polymer 
Fig. 3 Gaussian deconvolution of FTIR spectra of NaCMC \& $\mathrm{NaCMC}$ doped with a different weight $\%$ of $\mathrm{NaClO}_{4} \cdot \mathrm{H}_{2} \mathrm{O}$ salt between 1200 and $950 \mathrm{~cm}^{-1}$ regions
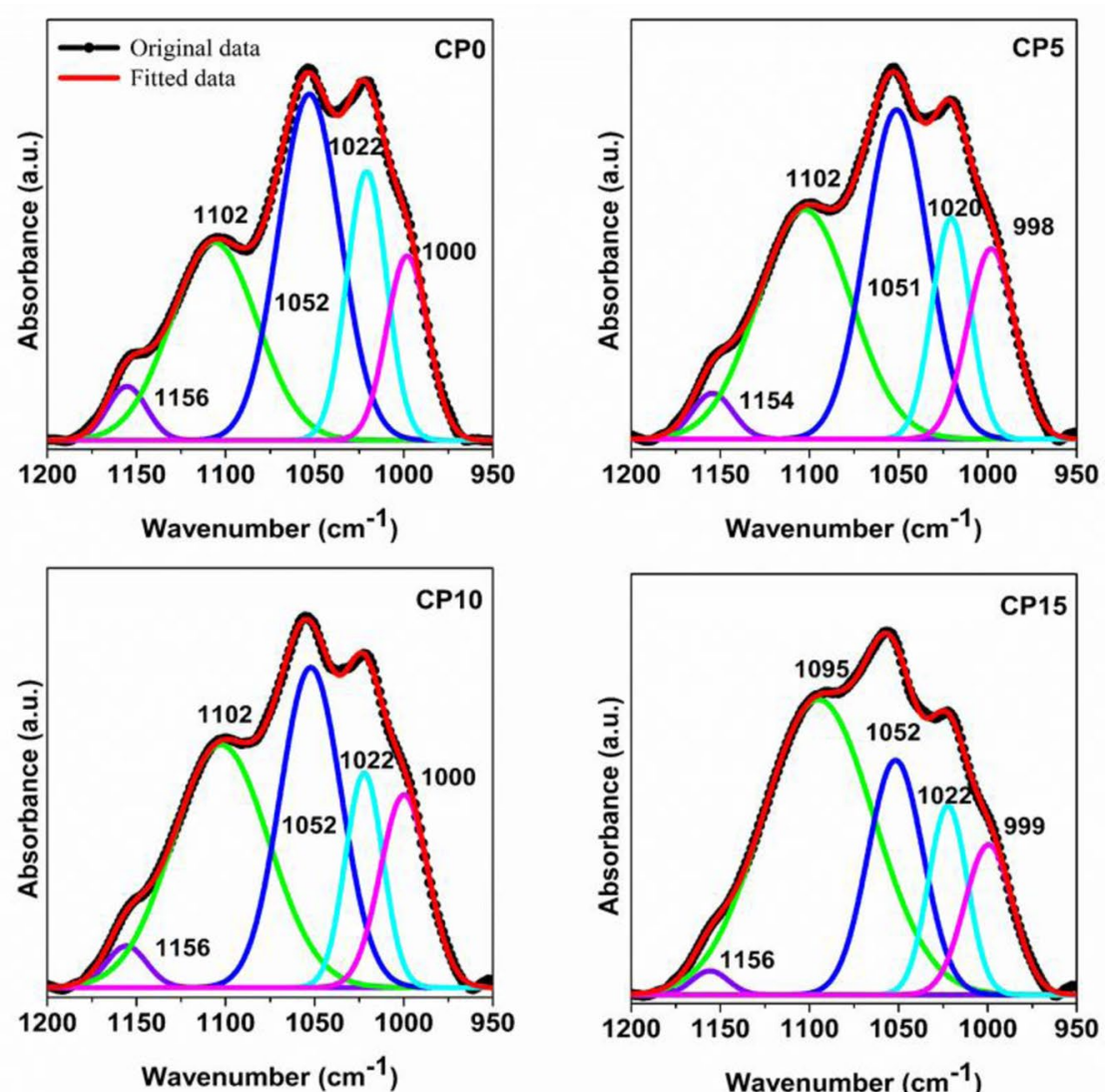

Wavenumber $\left(\mathrm{cm}^{-1}\right)$
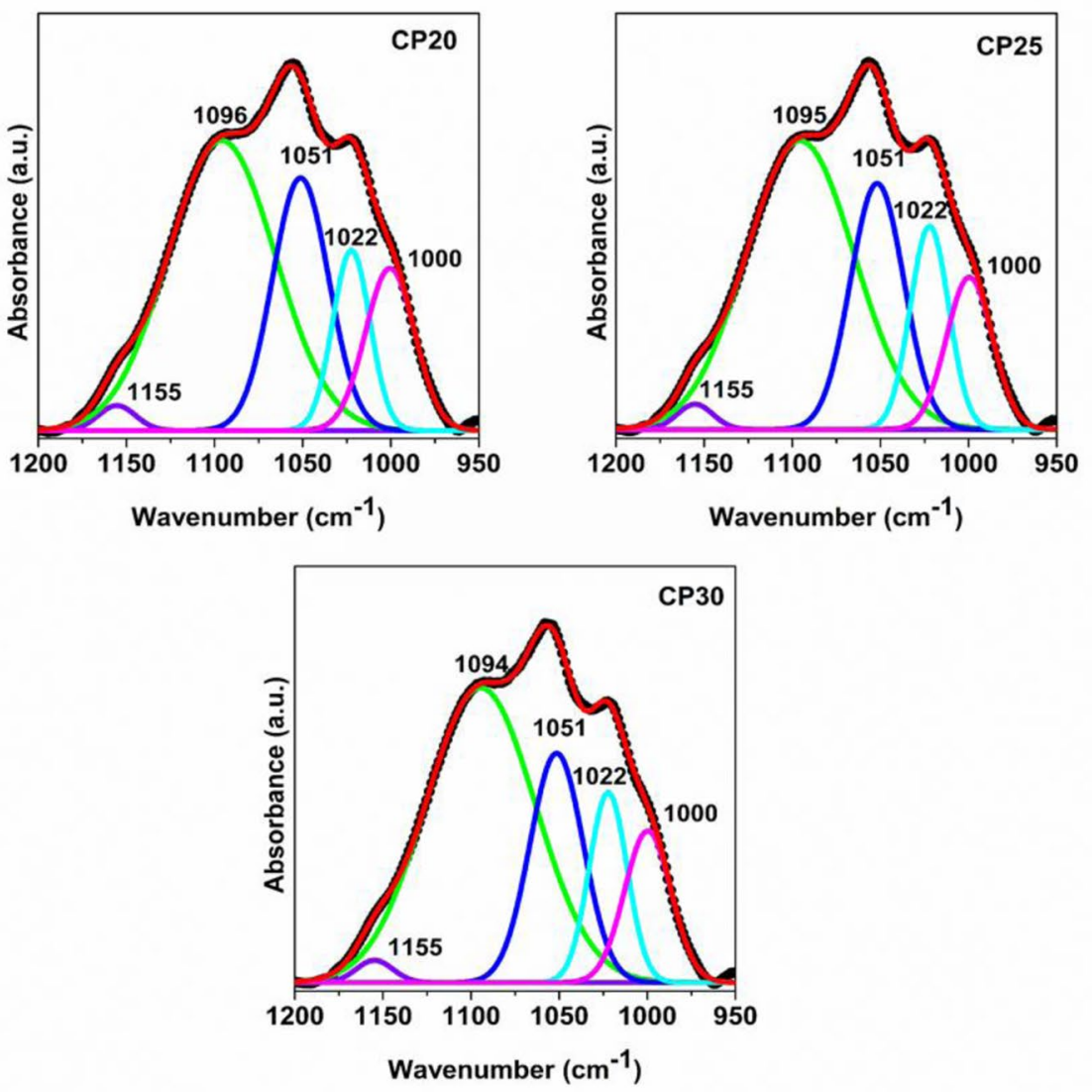


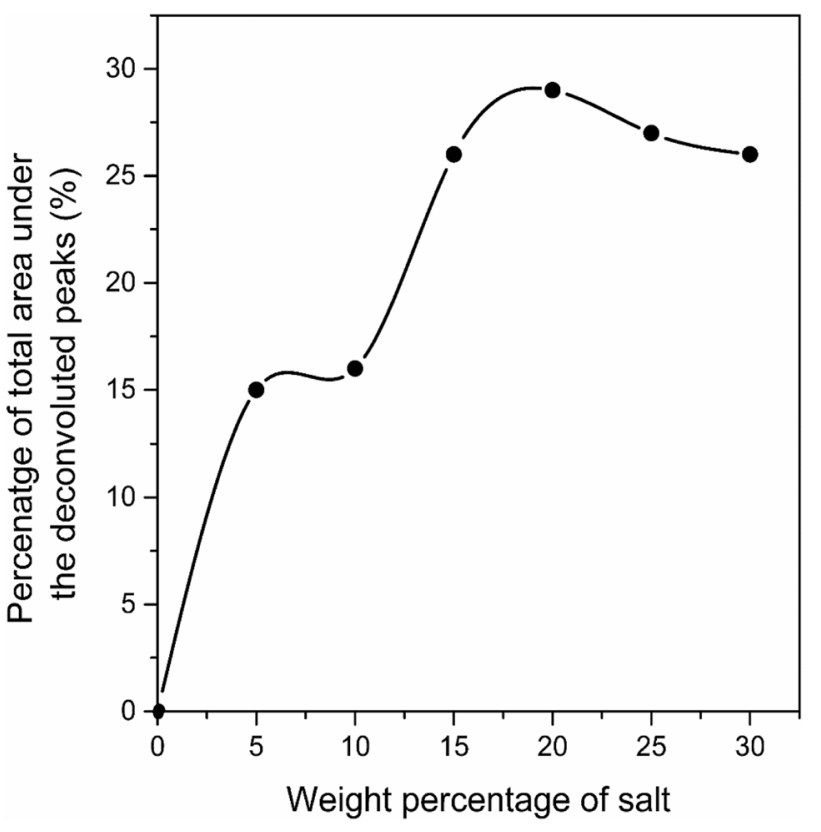

Fig. 4 Variation of the total area under ether region vs. salt concentration

electrolyte. The DSC thermogram exhibits a shallow and broad endothermic (characteristics of polysaccharides) peak between 30 and $150{ }^{\circ} \mathrm{C}$ correspondings to $T_{g}$. Since the glass transition is the second-order endothermic transition, it is observed as a step transition and not as a peak [22]. Incorporation of salt has not only led to a rise in $T_{g}$ as observed in Table 3 but also brought about broadening of DSC curve at $T_{g}$ - transition due to network heterogeneity implying the complexity in chain dynamics, caused by the ion-dipole interaction (especially anions with polymer chains) [23], owing to stiffening of the

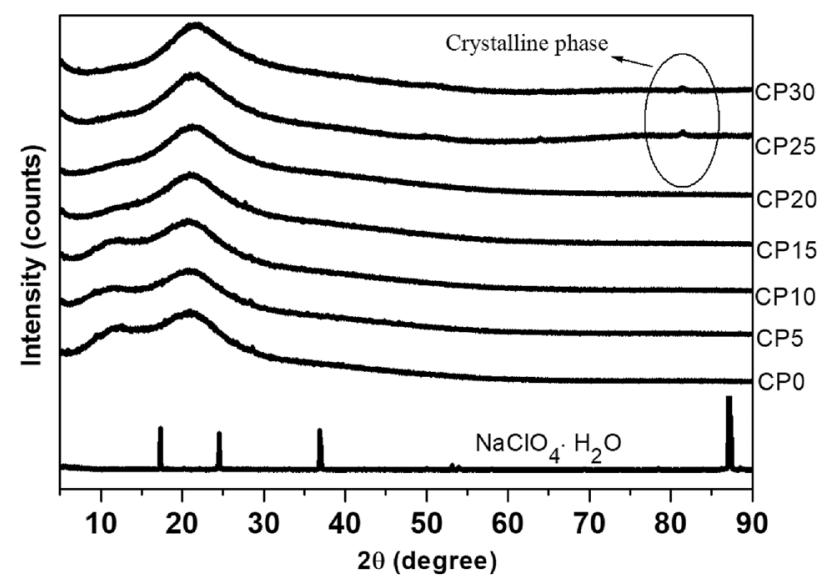

Fig. 5 XRD pattern of $\mathrm{NaClO}_{4} \cdot \mathrm{H}_{2} \mathrm{O}, \mathrm{NaCMC}$ and $\mathrm{NaCMC}: \mathrm{NaClO}_{4}$ $\cdot \mathrm{H}_{2} \mathrm{O}$ polymer electrolyte system polymer main chains that restrict the rotational motion and rearrangement of polymer chain segment due to iondipole interaction. An increase in $T_{g}$ concludes that stiffening of the polymer chain is not only caused by strong ion-dipole interaction (as observed from FTIR) but also attributed to the formation of transient crosslinking points between the main polymer chain via coordinated interaction between the carboxylate group $(\mathrm{C}=\mathrm{O})$ and $\mathrm{Na}^{+}$due to its availability as the free ion [24-26]. NaCMC exhibits thermal degradation from $250{ }^{\circ} \mathrm{C}$ onwards represented by exotherm peaks in the range from 250 to $320^{\circ} \mathrm{C}$, due to decarboxylation of the carboxylate group [7, 27, 28]. A second stage decomposition is observed in composites in the temperature range between 325 and $350{ }^{\circ} \mathrm{C}$ as an exotherm peak. The intensity of the exotherm depends on the salt concentration corresponds to the degradative reaction of the perchlorate anion [29,30], represented as, $2 \mathrm{ClO}_{4} \rightarrow \mathrm{Cl}_{2} \uparrow+4 \mathrm{O}_{2} \uparrow$

Incorporation of salt into the polymer matrix has improved the thermal stability of NaCMC, evident of microstructural change upon doping and shift of decomposition temperature $\left(T_{d}\right)$ to a higher temperature when the salt concentration increased indicates the strengthening of the bond formed between salt and the polymer which justifies the enhancement in the interaction.

\section{Dielectric studies}

The real $(\epsilon)^{\prime}$ and imaginary $\left(\epsilon^{\prime \prime}\right)$ part of complex permittivity, defined as, $\epsilon^{*}(\omega)=\epsilon^{\prime}(\omega)-j \epsilon^{\varepsilon}(\omega)$. A plot of $\varepsilon^{\prime}$ and $\varepsilon^{\prime \prime}$ as the function of frequency is respectively shown in Fig. 8a, b. The equations $\epsilon^{\varepsilon}=C_{p} t / \epsilon_{o} A$ and $\epsilon^{\varepsilon}=\epsilon^{\prime} \tan \delta$, Where $\mathrm{A}$ is the electrode/electrolyte contact area, $t$ is the thickness of the sample, $C_{p}$ is a geometrical capacitance and $\tan \delta$ is a loss factor was used to evaluate the real and imaginary parts of complex permittivity. The dielectric constant of the polymer electrolyte is directly linked with the number of free charge carriers. An initial high value of dielectric constant at the low-frequency window is attributed to space charge polarization event which is associated with the ions accumulation at the electrode-electrolyte interface. At a higher frequency window, the incapability of the ions to follow the applied electric field results in a decrease in dielectric permittivity due to less accumulation of charge carriers at the interface [31]. Since no relaxation peaks are observed in $\epsilon^{\varepsilon}$ vs $\log$ $\omega$ plot, this indicates that enhancement in conductivity is attributed to an increase in the number density of mobile ions and not because of structural relaxation of polymer main chain as evidenced in the DSC study. New crystalline peaks formed for higher salt concentration electrolyte is not because of the formation of ion aggregates/ion cluster, since $\epsilon^{\varepsilon}$ increased upon doping. 
Fig. 6 Deconvoluted XRD pattern of NaCMC and solid polymer electrolytes
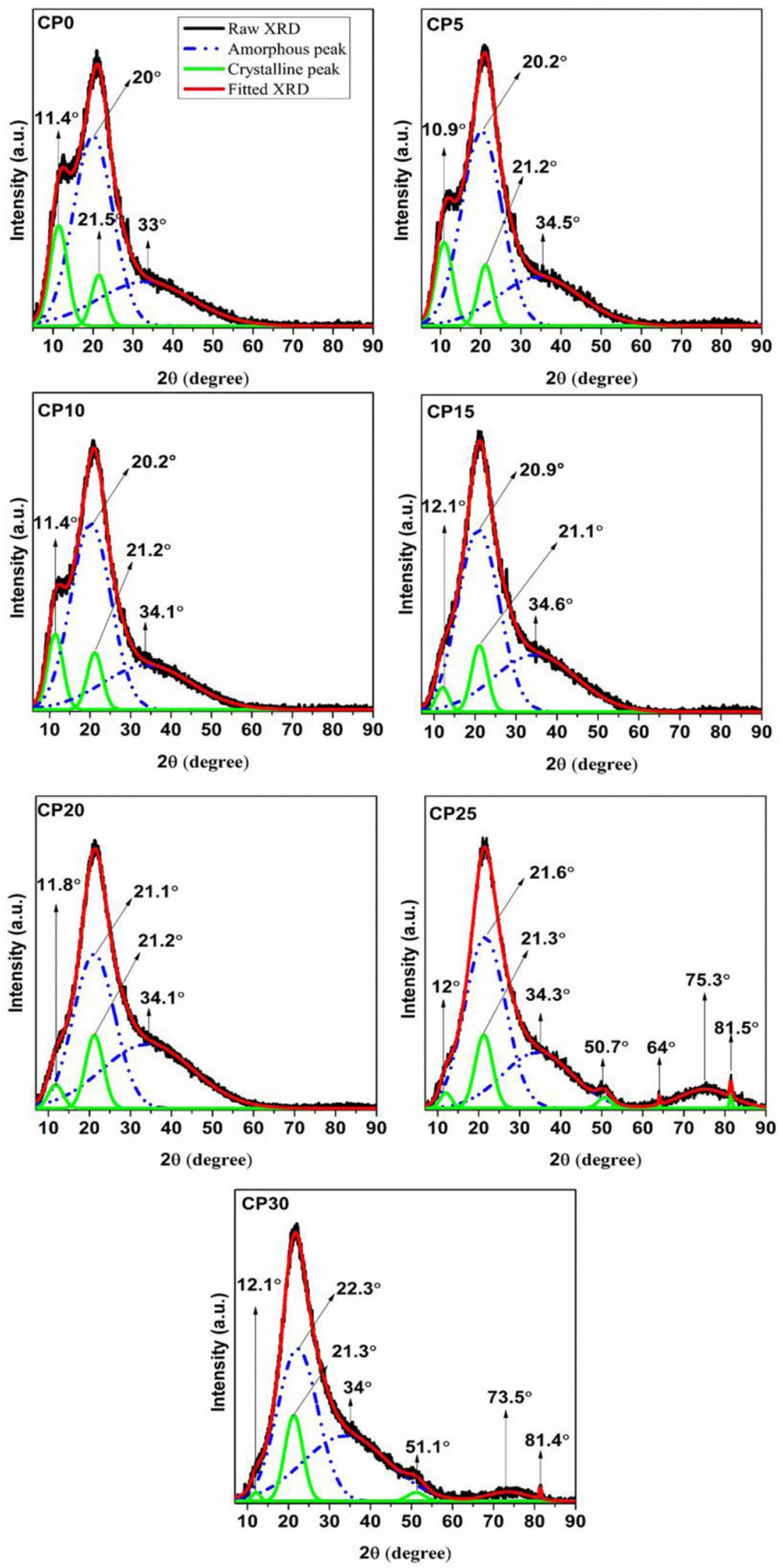
Table 2 Percentage of crystallinity of $\mathrm{NaCMC}$ and $\mathrm{NaCMC}: \mathrm{NaClO}_{4}$ $\cdot \mathrm{H}_{2} \mathrm{O}$ systems

\begin{tabular}{llll}
\hline Sample & $\begin{array}{l}\text { Crystallinity } \\
\text { area }\left(A_{C}\right)\end{array}$ & Amorphous area $\left(A_{a}\right)$ & $\begin{array}{l}\text { Crystallinity } \\
(c) \%\end{array}$ \\
\hline CP0 & 8028.34 & 37520.7 & 17.63 \\
CP5 & 4141.03 & 21063.61 & 16.43 \\
CP10 & 4934.39 & 27682.37 & 15.13 \\
CP15 & 3289.65 & 29393.5 & 10.07 \\
CP20 & 8892.80 & 65751.1 & 11.91 \\
CP25 & 7182.04 & 51654.14 & 12.21 \\
CP30 & 7415.30 & 57864.94 & 12.81 \\
\hline
\end{tabular}

In Fig. 9, a single relaxation peak has been observed in the frequency-dependent dielectric loss tangent curve, which corresponds to the conductivity relaxation time of ionic conduction. The maximum at the single frequency happens at resonance due to the matching of electric field frequency with the frequency of the rotating molecule. The maxima of loss factor $(\tan \delta$ ) shift towards the high-frequency end causing a reduction in relaxation time indicate faster ion migration from one coordinate site to the other [32]. The increase in peak height upon the increase in dopant concentration is attributed to an increase in carrier concentration. The formation of a new crystalline phase has affected the relaxation peak since a significant shift has not been observed.

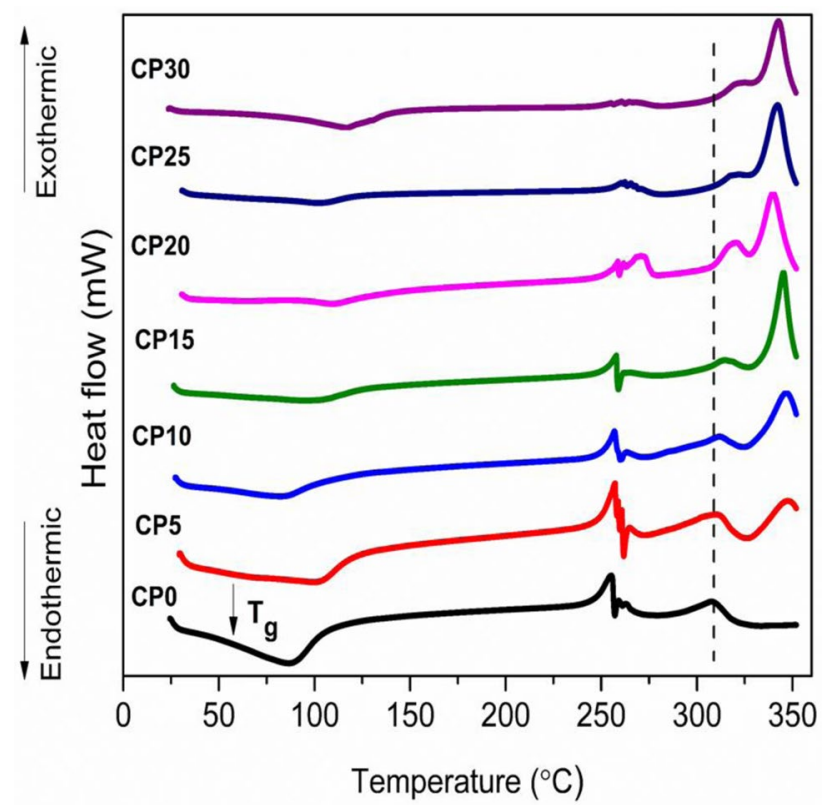

Fig. 7 DSC thermograph of $\mathrm{NaCMC}$ and $\mathrm{NaCMC}$ : $\mathrm{NaClO}_{4} \cdot \mathrm{H}_{2} \mathrm{O}$ polymer electrolyte system
Table $3 T_{g}$ and $T_{d}$ from DSC

\begin{tabular}{lll}
\hline Sample & $\begin{array}{l}T_{g} \\
\left({ }^{\circ} \mathrm{C}\right)\end{array}$ & $\begin{array}{l}T_{d} \\
\left({ }^{\circ} \mathrm{C}\right)\end{array}$ \\
\hline CP0 & 54 & - \\
CP5 & 62 & 345 \\
CP10 & 56 & 346 \\
CP15 & 63 & 345 \\
CP20 & 90 & 340 \\
CP25 & 83 & 342 \\
CP30 & 84 & 342 \\
\hline
\end{tabular}

\section{EIS measurements}

The AC impedance spectroscopic technique was utilized to evaluate the conductivity properties of SPEs. A Nyquist plot that comprises a low frequency tilted spike and highfrequency depressed semicircle has been observed in Fig. 10. To arrive at the equivalent circuit model (Fig. 11), EIS spectrum analyzer software was employed to fit the Nyquist plot with an average error percentage being less than $5 \%$. The model gives a picture of the process that is taking place in the applied frequency window in the electrode-electrolyte system. Low frequency tilted spike can be represented by a constant phase element $\left(\mathrm{CPE}_{1}\right)$ attributed to the blocking effect by electrodes (space charge polarization). A depressed or distorted semicircle at high frequency is symbolized by a resistor of bulk resistance $\left(\mathrm{R}_{\mathrm{b}}\right)$ in parallel with CPE $\left(\mathrm{CPE}_{2}\right)$ indicating the bulk process of ion-conduction and dipolar polarization that are happening at the same time, respectively [33]. The bulk conductivity was evaluated from the relation $\sigma=t / R_{b} A$, where $R_{b}$ is resistance of the specimen, $A$ is area of the electrode/electrolyte contact and $t$ is the thickness of the sample and the calculated values are tabulated in Table 4. A shrink and falling-off of the semicircle region with an increase in salt concentration indicated a drop in ionic resistance.

\section{AC conductivity study}

The variation in the frequency-dependent conductivity spectra, as seen from Fig. 12 comprises three distinct regions. The low-frequency dispersive region corresponding to space charge polarization with the lowest conductivity value due to the non-availability of mobile ions in bulk. Frequency-independent plateau region corresponding to ionconduction in specimen connected with DC conductivity as per the Jonscher universal power-law given by, $\sigma_{a c}(\omega)=\sigma_{d c}+A \omega^{s}$, where $A$ and $s$ are respectively referred to as material parameters and the power-law dispersive region $[34,35]$. The value of DC conductivity is obtained by taking intercept of $\sigma_{a c}$ at $\omega=0$ shows good agreement with the bulk conductivity obtained from the Nyquist plot and are 
Fig. 8 (a) Variation of $\epsilon^{\prime} \&$ (b) $\epsilon^{\varepsilon}$ as a function of frequency for electrolyte with different salt concentrations

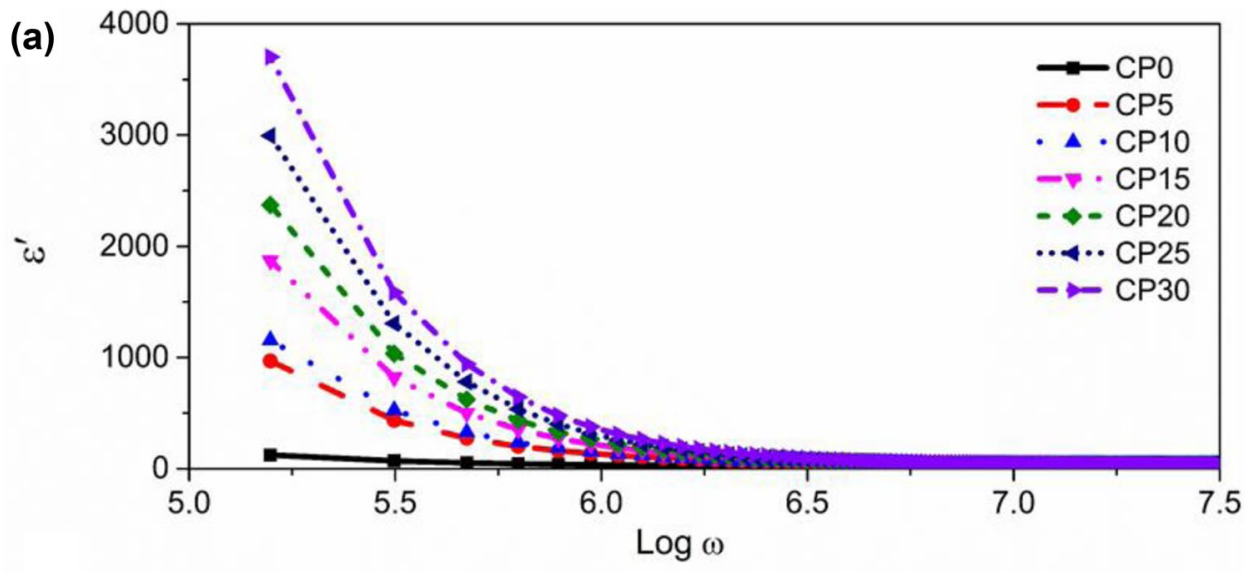

(b)

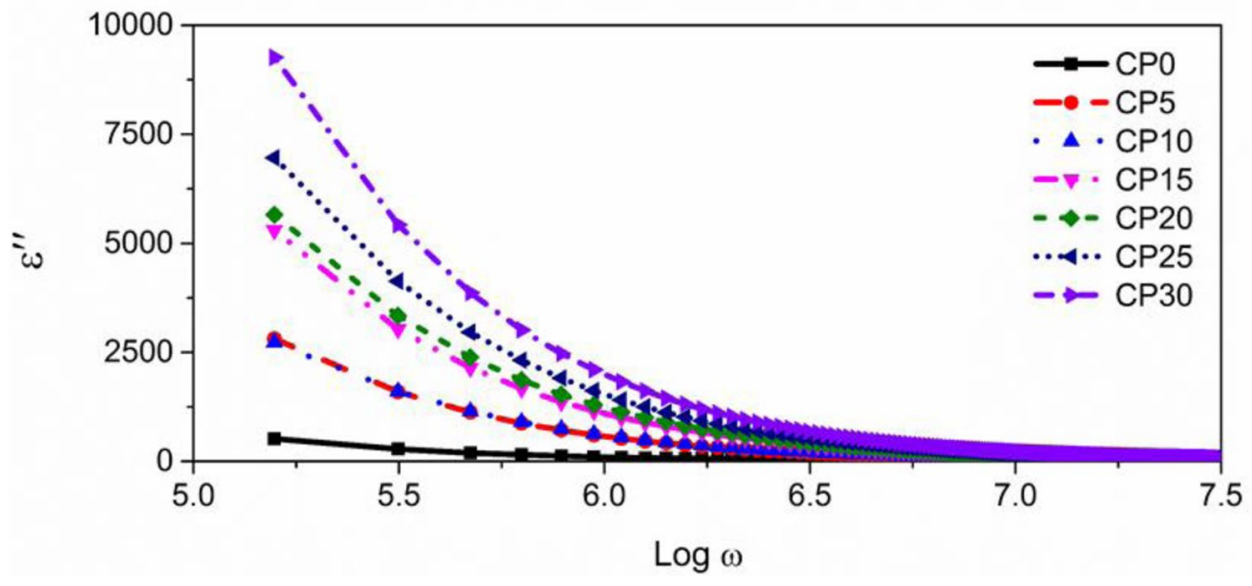

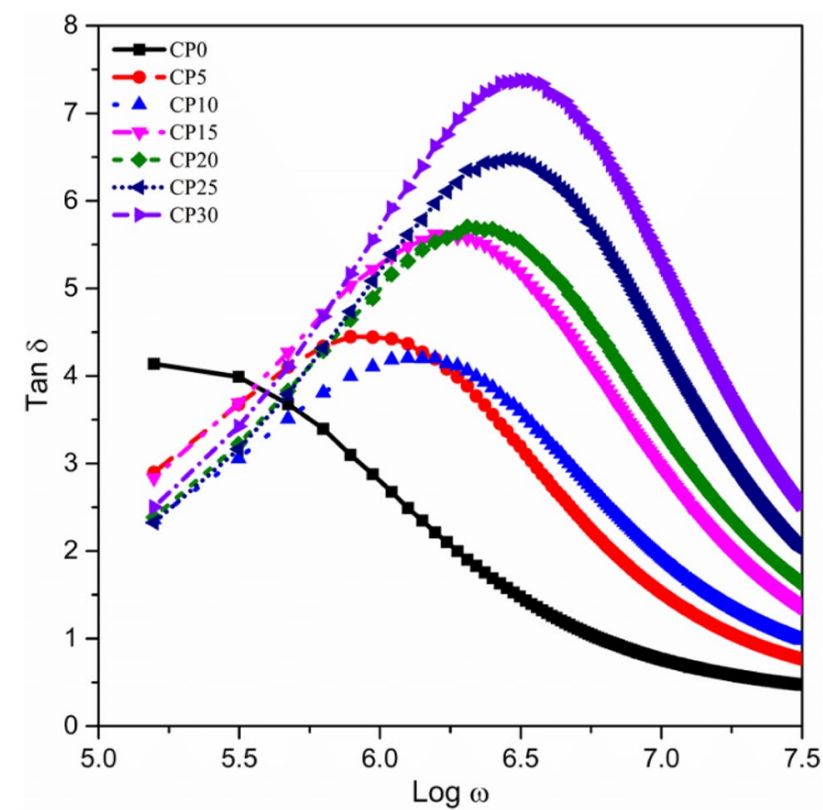

Fig. 9 Variation of loss factor ( $\tan \delta$ ) with frequency for NaCMCbased solid polymer electrolyte systems

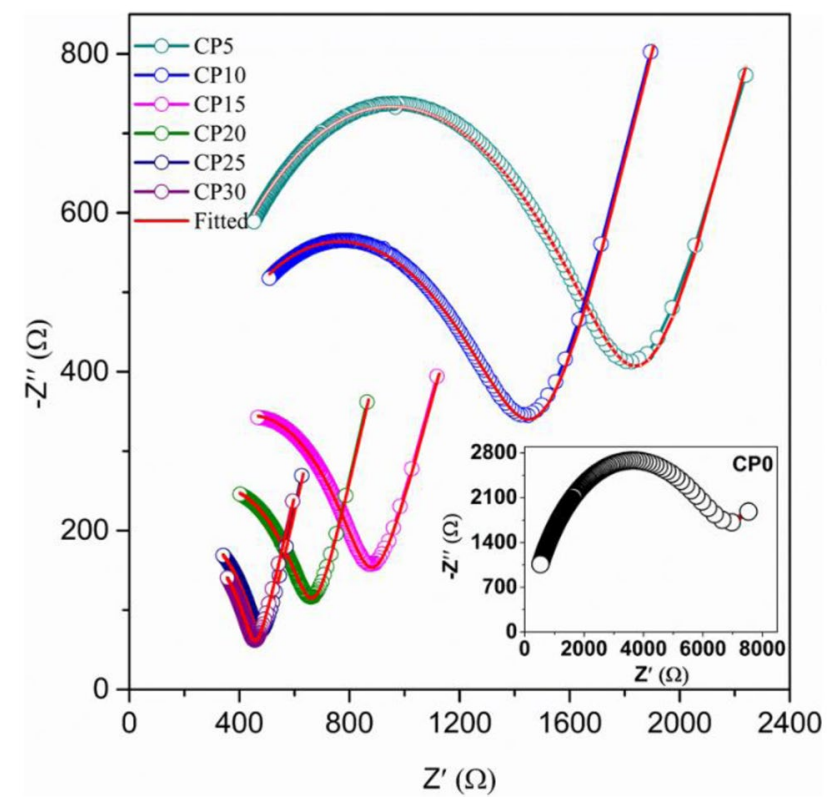

Fig. 10 Nyquist plot and their corresponding fitted points for $\mathrm{NaCMC}$ with different $\mathrm{NaClO}_{4} \cdot \mathrm{H}_{2} \mathrm{O}$ concentration 


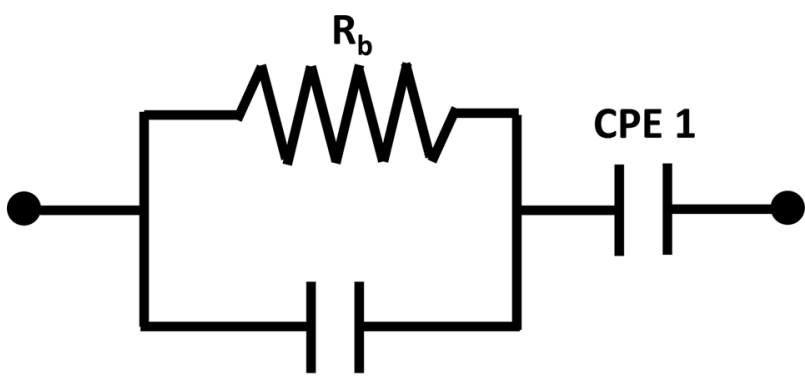

CPE 2

Fig. 11 Equivalent circuit model representing complex impedance plot

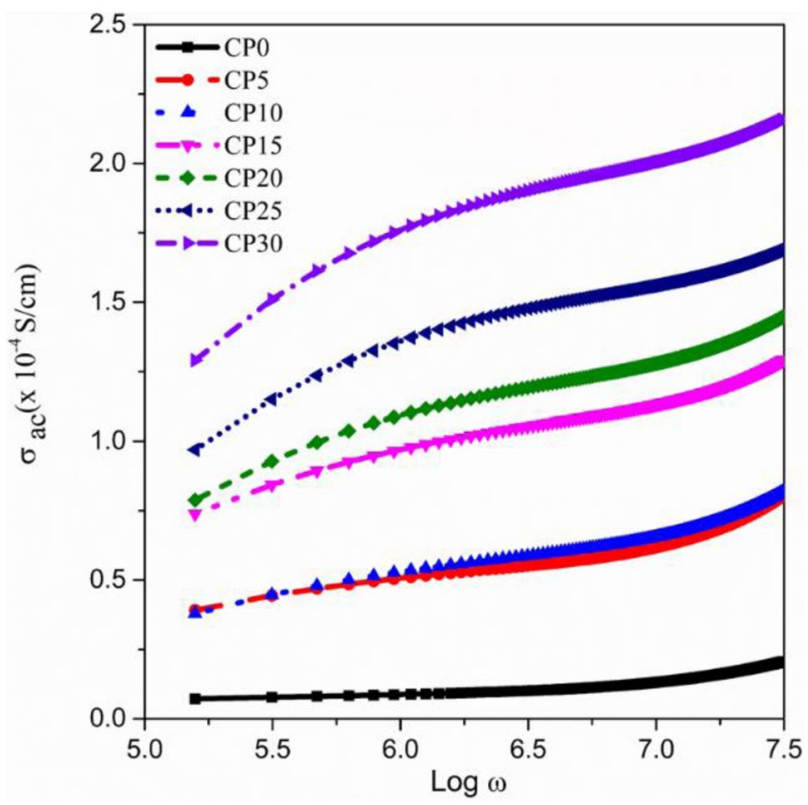

Fig. 12 Frequency-dependent conductivity spectra of $\mathrm{NaCMC}$ with different $\mathrm{NaClO}_{4} \cdot \mathrm{H}_{2} \mathrm{O}$ concentration

tabulated in Table 4. Improvement in the ionic-conductivity of SPE is observed when there is (i) enhancement in the amorphous content in polymer matrix upon doping (ii) decrease in glass transition temperature (iii) enhancement in the number density of free ions (iv) increase in free ion mobility.

The variation of $\epsilon^{\prime}, \sigma, T_{g}$ and ${ }_{c}$ as the function of salt content can be divided into two regions as illustrated in Fig. 13. In region I, a similar trend for $\epsilon^{\prime}$, ionic conductivity and $\mathrm{T}_{\mathrm{g}}$ has been observed, where there is a gradual increase in $\mathrm{T}_{\mathrm{g}}$. In region I, a monotonically increase in conductivity is due to the availability of free ions as proved in the FTIR deconvolution analysis, which has masked the contribution of lowering of crystallinity that assists ion transport. A slight variation in trend, especially in $\sigma$, was observed for CP15 (exhibited a low value of crystallinity), due to ease migration of ions attributed by the enhancement in amorphous content creating bigger transfer space and low energy barrier. Lowering of $T_{g}$ for CP10 and a sudden rise in $T_{g}$ for CP20 has been observed. The former one is due to decreasing and the latter one is due to the increasing amount of coordination of sodium cation with ether group as proved from the area under the deconvoluted FTIR curve. In Region II, a linear relationship between $T_{g}$ and salt concertation as well as the prominent variation of $\sigma$ have not been observed due to the formation of transient crosslinks of $\mathrm{Na}^{+}$ions with $\mathrm{C}=\mathrm{O}$ and formation of $\mathrm{Na}^{+} \ldots \mathrm{ClO}_{4}^{-} \cdots \mathrm{Na}^{+}$bridges between the polymer chains that have led to the formation of new crystalline phase resulted in the fall of average free volume that has affected ion migration. Hence prominent variation in ionic conductivity has not been observed in spite of the availability of free ions [36]. The interaction between the polymer and the ions in two regions are graphically illustrated in Fig. 14. Further, a decrease and saturation in $T_{g}$ were observed for higher salt concentration (CP25 \& CP30) in the polymer matrix which may be due to limited availability of the ether group (decrease in area under FTIR curve) and not because of salt precipitation. Since the variation of $\epsilon^{\prime}$ follows the same trend as the ionic conductivity, this implied that the ion aggregates/ ion association/ion pairing has not occurred. Saturation of $T_{g}$ at higher salt concentration may be attributed to phase separation, degree of crystallization and contamination effect [37]. In this case, we believe that circumstance is the due formation of the new crystalline
Table 4 Bulk resistance, Bulk conductivity and DC conductivity of NaCMC: $\mathrm{NaClO}_{4} \cdot \mathrm{H}_{2} \mathrm{O}$ solid polymer electrolytes at room temperature

\begin{tabular}{lllll}
\hline Sample & $\begin{array}{l}\text { Bulk resistance } \\
\left(\mathrm{R}_{\mathrm{b}}\right) \Omega\end{array}$ & $\begin{array}{l}\text { Bulk conductivity } \\
\left(\mathrm{Scm}^{-1}\right)\end{array}$ & $\begin{array}{l}\text { DC conductivity }\left(\sigma_{\mathrm{dc}}\right) \\
\text { at } \omega=0\left(\mathrm{Scm}^{-1}\right)\end{array}$ & Relaxation time $\tau(\mathrm{s})$ \\
\hline $\mathrm{CP} 0$ & 6919.11 & $8.32 \times 10^{-6}$ & $10.40 \times 10^{-6}$ & - \\
$\mathrm{CP} 5$ & 1755.1 & $5.58 \times 10^{-5}$ & $5.80 \times 10^{-5}$ & $1.27 \times 10^{-6}$ \\
$\mathrm{CP} 10$ & 1393.5 & $6.09 \times 10^{-5}$ & $6.26 \times 10^{-5}$ & $7.96 \times 10^{-7}$ \\
$\mathrm{CP} 15$ & 835.92 & $1.11 \times 10^{-4}$ & $1.10 \times 10^{-4}$ & $6.36 \times 10^{-7}$ \\
$\mathrm{CP} 20$ & 641.31 & $1.25 \times 10^{-4}$ & $1.24 \times 10^{-4}$ & $4.90 \times 10^{-7}$ \\
$\mathrm{CP} 25$ & 459.95 & $1.57 \times 10^{-4}$ & $1.54 \times 10^{-4}$ & $3.54 \times 10^{-7}$ \\
$\mathrm{CP} 30$ & 443.51 & $2.00 \times 10^{-4}$ & $1.94 \times 10^{-4}$ & $3.18 \times 10^{-7}$ \\
\hline
\end{tabular}




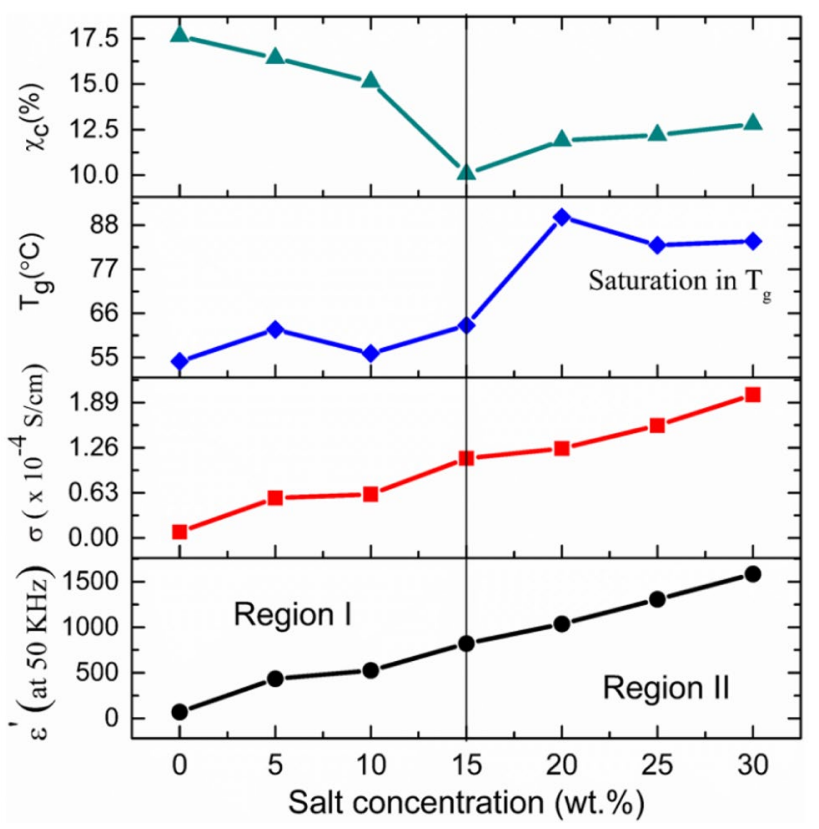

Fig. 13 Variation of $\epsilon^{\prime}, \sigma, T_{g}$ and ${ }_{c}$ as the function of salt concentration

phase. The formation of a new crystalline phase has not deteriorated the ionic conductivity due to the presence of free ions that have participated in the transient crosslinks.
In conclusion, the major factor determining the ionic conductivity in this electrolyte system is the number of charge carriers and polymer electrolyte dynamics.

\section{Mechanical properties}

The least attention has been given to the mechanical strength of the polymer electrolyte and must be taken into account during large-scale manufacturing of batteries. The polymer electrolyte should not be brittle in order to have ease elastic relaxation due to the stress generated during the process of assembly, storage and consumption. For electrochemical applications especially the battery, the polymer electrolyte must not be brittle so that it can relax elastically during charging and discharging cycles. The stress-strain curve of NaCMC is depicted in Fig. 15. It can be seen that the NaCMC-based SPE has a lower elongation at break of about $3 \%$ and hence possess brittle nature. The films have exhibited brittleness to softness texture as the salt concentration in the pristine polymer increased. The mechanical properties of the films were analyzed in terms of tensile strength, Young's modulus and elongation at break and are tabulated in Table 5. Figure 15 shows the typical stress-strain curve of $\mathrm{NaCMC}-\mathrm{NaClO}_{4} \cdot \mathrm{H}_{2} \mathrm{O}$ solid polymer electrolyte films. The mechanical properties are affected by the content of the crystalline phase in the SPE. But, in this case, the effect of crystalline/amorphous

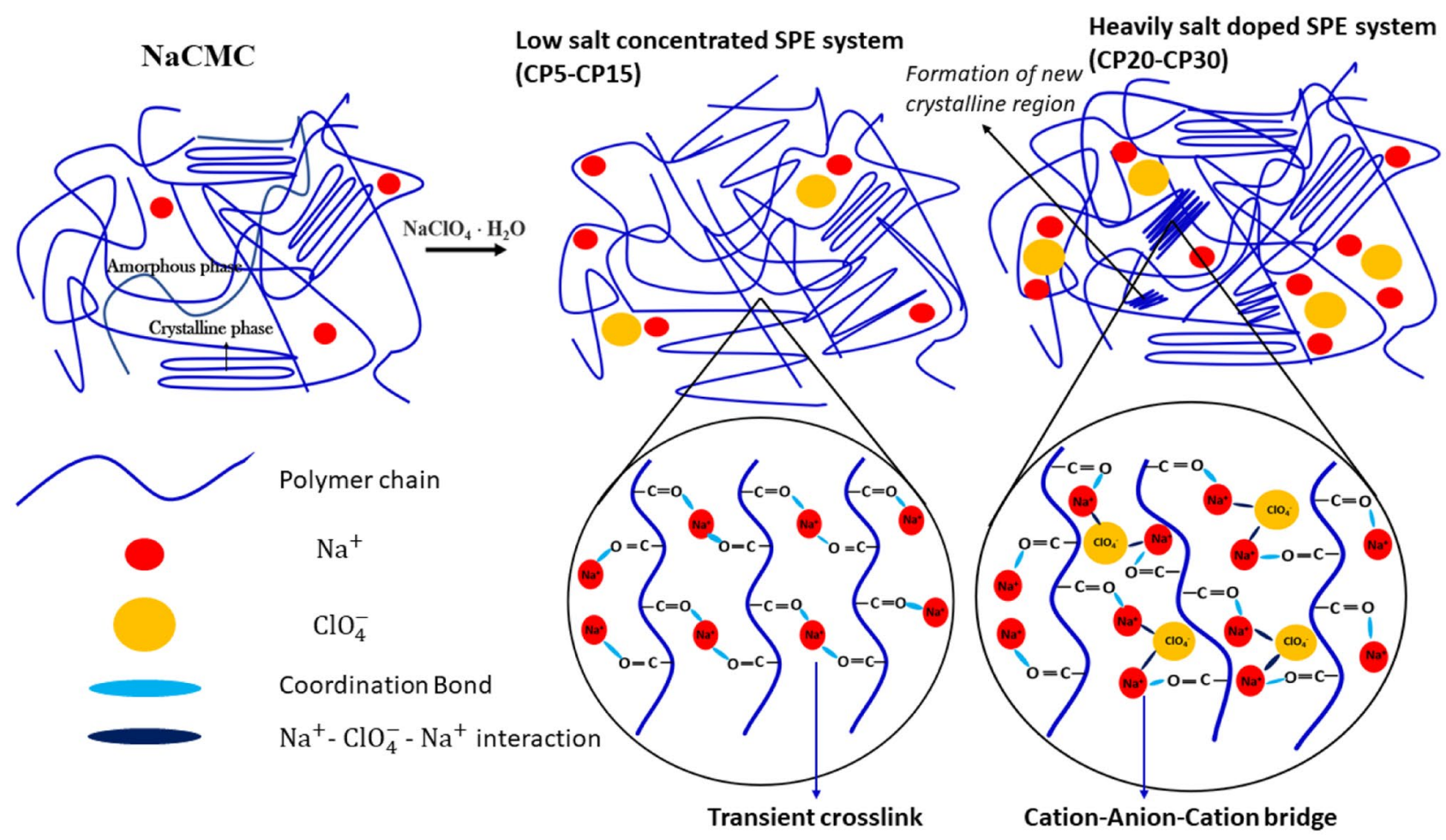

Fig. 14 Schematic illustration of polymer-ion interaction 


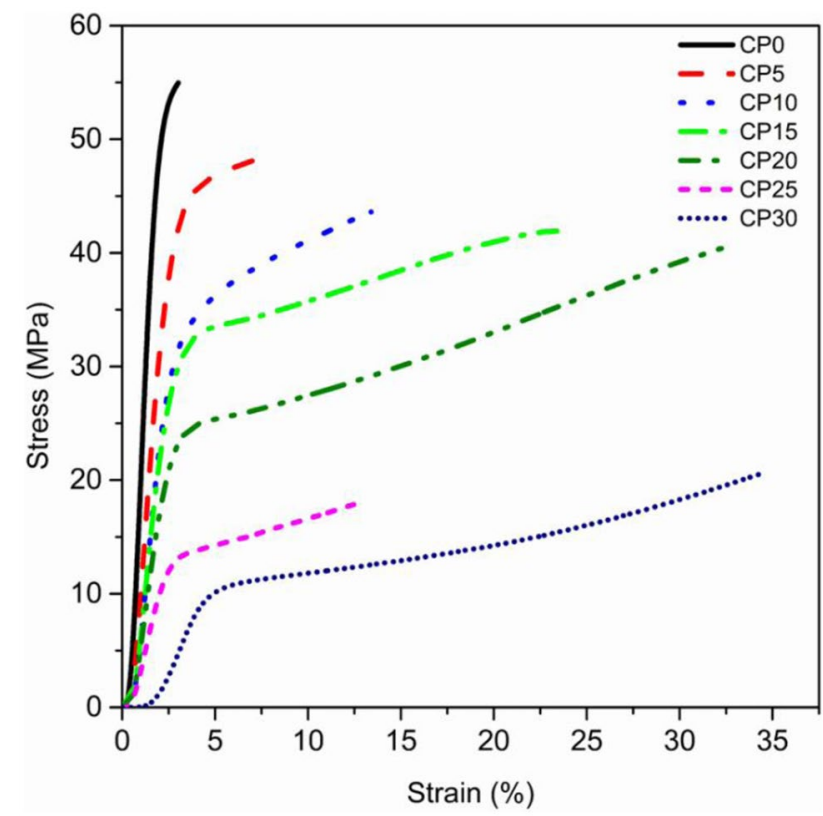

Fig. 15 Mechanical behaviour of polymer/solid polymer electrolyte

Table 5 Mechanical properties of polymer/solid polymer electrolyte films

\begin{tabular}{llll}
\hline Sample & $\begin{array}{l}\text { Tensile Strength } \\
\text { (MPa) }\end{array}$ & $\begin{array}{l}\text { Elongation at } \\
\text { Break (\%) }\end{array}$ & $\begin{array}{l}\text { Youngs } \\
\text { Modulus } \\
\text { (MPa) }\end{array}$ \\
\hline CP0 & 55.006 & 3.028 & 1912.074 \\
CP5 & 48.11 & 7.152 & 1763.258 \\
CP10 & 43.627 & 13.416 & 1351.135 \\
CP15 & 41.92 & 23.414 & 1262.653 \\
CP20 & 40.501 & 32.515 & 973.387 \\
CP25 & 17.857 & 12.486 & 557.869 \\
CP30 & 20.501 & 7.079 & 544.206 \\
\hline
\end{tabular}

phase content on the mechanical properties of SPEs has been masked by the decrease in the weight $\%$ of polymer with doping concentration. Therefore, a decreasing trend in mechanical properties has been observed as the salt content in the SPE system is reduced. Electrolyte CP15 with ionic conductivity of $1.11 \times 10^{-4} \mathrm{Scm}^{-1}$ has sufficient mechanical strength as reported by Liping et al. [38] to be incorporated in an electrochemical cell.

\section{Conclusion}

Biodegradable solid polymer electrolyte based on NaCMC as polymer matrix doped with $\mathrm{NaClO}_{4} \cdot \mathrm{H}_{2} \mathrm{O}$ have been prepared by solution cast technique. The complex formation of polymer salt has been justified by FTIR, XRD and DSC analysis. FTIR deconvolution in the ether region has not shown any significant variation in the area under the peak/ band pattern for higher dopant concentration, due to the limited availability of the ether group. Formation of transient crosslinks between the polymer chains by the coordination bond between free $\mathrm{Na}^{+}$cation and $\mathrm{C}=\mathrm{O}$ has led to a hike in $T_{g}$ (in Region I). Later on, the participation of $\mathrm{ClO}_{4}^{-}$in transient crosslink has led to the abrupt hike in $T_{g}$. The saturation of $T_{g}$ observed (sample CP25 and CP30) is not because of salt precipitation as per the dielectric study. The anomalous behaviour of $T_{g}$ at higher salt concentration and impact of salt precipitation/ion-pairing on ionic conductivity is not clear and need to be explored. The formation of a new crystalline phase has not deteriorated the ionic conductivity for higher salt concentration due to the presence of free ions that are available for conduction. Sample CP15 having ionic conductivity of $1.11 \times 10^{-4} \mathrm{Scm}^{-1}$ with low crystallinity and tensile strength of $42 \mathrm{MPa}$ and is the best choice as the solid polymer electrolyte in an electrochemical cell.

Acknowledgements The authors are thankful to UGC DAE Consortium for Scientific Research (Kolkata Centre), Government of India for financial assistance in the form of Research Project (Sanction No. UGC-DAE-CSR-KC/CRS/19/MS010/0931/0971 dated 10-05-2019). The authors are thankful to Dr. Saraswati P. Masti, Principal Investigator of DST-SERB project (Sanctioned No. SB/EMEQ-213/2014 dated 29-01-2016), Department of Chemistry, Karnataka University's Karnataka Science College, Dharwad, Karnataka, India.

Funding Open access funding provided by Manipal Academy of Higher Education, Manipal.

\section{Declarations}

Conflict of interest The authors declare that there are no conflicts of interest exist.

Open Access This article is licensed under a Creative Commons Attribution 4.0 International License, which permits use, sharing, adaptation, distribution and reproduction in any medium or format, as long as you give appropriate credit to the original author(s) and the source, provide a link to the Creative Commons licence, and indicate if changes were made. The images or other third party material in this article are included in the article's Creative Commons licence, unless indicated otherwise in a credit line to the material. If material is not included in the article's Creative Commons licence and your intended use is not permitted by statutory regulation or exceeds the permitted use, you will need to obtain permission directly from the copyright holder. To view a copy of this licence, visit http://creativecommons.org/licenses/by/4.0/.

\section{References}

1. Marchiori CFN, Carvalho RP, Ebadi M, Brandell D, Araujo CM (2020) Understanding the Electrochemical Stability Window of Polymer Electrolytes in Solid-State Batteries from Atomic-Scale 
Modeling: The Role of Li-Ion Salts. Chem Mater 32(17):72377246. https://doi.org/10.1021/acs.chemmater.0c01489

2. Wang Y et al (2020) Flexible, stable, fast-ion-conducting composite electrolyte composed of nanostructured Na-super-ionconductor framework and continuous Poly(ethylene oxide) for all-solid-state Na battery. J Power Sources 454:227949. https:// doi.org/10.1016/j.jpowsour.2020.227949

3. Marcinek M et al (2015) Electrolytes for Li-ion transport Review. Solid State Ion 276:107-126. https://doi.org/10.1016/j. ssi.2015.02.006

4. Hanqing D et al (2021) A Review of Modification Methods of Solid Electrolytes for All-Solid-State Sodium-Ion Batteries. Energy Technol 9:2000682. https://doi.org/10.1002/ente.202000682

5. Zhang X, Daigle J-C, Zaghib K (2020) Comprehensive Review of Polymer Architecture for All-Solid-State Lithium Rechargeable Batteries. Materials 13(11). https://doi.org/10.3390/ma13112488

6. Selvakumar SYNM Bhat DK (2018) Biopolymer Electrolytes: Fundamentals and Applications in Energy Storage. Elsevier

7. Biswal DR, Singh RP (2004) Characterisation of carboxymethyl cellulose and polyacrylamide graft copolymer. Carbohydr Polym 57(4):379-387. https://doi.org/10.1016/j.carbpol.2004.04. 020

8. García A, Culebras M, Collins MN, Leahy JJ (2018) Stability and rheological study of sodium carboxymethyl cellulose and alginate suspensions as binders for lithium ion batteries. J Appl Polym Sci 135(17):46217. https://doi.org/10.1002/app.46217

9. Patra J et al (2018) A Water-Soluble NaCMC/NaPAA Binder for Exceptional Improvement of Sodium-Ion Batteries with an SnO2Ordered Mesoporous Carbon Anode. ChemSusChem 11:22, pp. 3923-3931. https://doi.org/10.1002/cssc.201801962.

10. Zhao T, Meng Y, Ji R, Wu F, Li L, Chen R (2019) Maintaining structure and voltage stability of Li-rich cathode materials by green water-soluble binders containing $\mathrm{Na}+$ ions. J Alloys Compd 811:152060. https://doi.org/10.1016/j.jallcom.2019. 152060

11. Noor I (2020) Determination of charge carrier transport properties of gellan gum-lithium triflate solid polymer electrolyte from vibrational spectroscopy. High Perform Polym 32(2):168-174. https://doi.org/10.1177/0954008319890016

12. Supriya KS, Ismayil, Shreedatta H, Ravindrachary V, Ganesh S, Bhajantri RF, Saraswati PM (2021) Dielectric relaxations and ion transport study of $\mathrm{NaCMC}: \mathrm{NaNO}_{3}$ solid polymer electrolyte films. Ionics 27:2509-2525. https://doi.org/10.1007/ s11581-021-04023-y

13. Gupta S, Varshney PK (2019) Effect of plasticizer on the conductivity of carboxymethyl cellulose-based solid polymer electrolyte. Polym Bull 76(12):6169-6178. https://doi.org/10.1007/ s00289-019-02714-1

14. Rajeh A, Morsi MA, Elashmawi IS (2019) Enhancement of spectroscopic, thermal, electrical and morphological properties of polyethylene oxide/carboxymethyl cellulose blends: Combined FT-IR/DFT. Vacuum 159:430-440. https://doi.org/10.1016/j. vacuum.2018.10.066

15. Liang Y-H, Wang C-C, Chen C-Y (2008) Synthesis and characterization of a new network polymer electrolyte containing polyether in the main chains and side chains. Eur Polym J 44(7):23762384. https://doi.org/10.1016/j.eurpolymj.2008.05.006

16. Firsov SP, Zhbankov RG, Petrov PT, Shingel KI, Tsarenkov VM (1999) Analysis of dextran and pullulan molecular fraction structure by the method of IR-spectroscopy in Spectroscopy of Biological Molecules: New Directions: 8th European Conference on the Spectroscopy of Biological Molecules, 29 August-2 September 1999, Enschede, The Netherlands, J. Greve, G. J. Puppels, and C. Otto, Eds. Dordrecht: Springer Netherlands, pp 323-324. https:// doi.org/10.1007/978-94-011-4479-7_144
17. Cael JJ, Koenig JL, Blackwell J (1974) Infrared and raman spectroscopy of carbohydrates: Part IV. Identification of configuration- and conformation-sensitive modes for D-glucose by normal coordinate analysis. Carbohyd Res 32(1):79-91. https://doi.org/ 10.1016/S0008-6215(00)82465-9

18. Vasko PD, Blackwell J, Koenig JL (1972) Infrared and raman spectroscopy of carbohydrates.: Part II: Normal coordinate analysis of $\alpha$-D-glucose. Carbohyd Res 23(3):407-416. https://doi.org/ 10.1016/S0008-6215(00)82690-7

19. Hadjichristov GB, Ivanov TE, Marinov YG, Koduru HK, Scaramuzza N (2019) PEO-PVP-NaIO4 Ion-Conducting Polymer Electrolyte: Inspection for Ionic Space Charge Polarization and Charge Trapping. Phys Status Solidi A 216(13):1800739. https:// doi.org/10.1002/pssa.201800739

20. de Melo EM, Clark JH, Matharu AS (2017) The Hy-MASS concept: hydrothermal microwave assisted selective scissoring of cellulose for in situ production of (meso)porous nanocellulose fibrils and crystals. Green Chem 19(14):3408-3417. https://doi.org/10. 1039/C7GC01378G.

21. Sampathkumar L, Christopher Selvin P, Selvasekarapandian S, Perumal P, Chitra R, Muthukrishnan M (2019) Synthesis and characterization of biopolymer electrolyte based on tamarind seed polysaccharide, lithium perchlorate and ethylene carbonate for electrochemical applications. Ionics 25(3):1067-1082. https:// doi.org/10.1007/s11581-019-02857-1

22. Enrique SG, Eduardo VL (2013) Handbook of Polymer Synthesis, Characterization, and Processing, 1st edn. Wiley, New York. https://doi.org/10.1002/9781118480793

23. He R, Kyu T (2016) Effect of plasticization on ionic conductivity enhancement in relation to glass transition temperature of crosslinked polymer electrolyte membranes. Macromolecules 49(15):5637-5648. https://doi.org/10.1021/acs.macromol.6b00918.

24. Huh PH, Choi MG, Jo NJ, Lee JK, Lee JO, Yang W (2004) Effect of salt concentration on the glass transition temperature and ionic conductivity of poly(ethylene glycol)-polyurethane/LiClO4 complexes. Macromol Res 12(4):422-426. https://doi.org/10.1007/ BF03218421

25. Kim JH, Min BR, Kim CK, Won J, Kang YS (2001) Role of Transient Cross-Links for Transport Properties in Silver-Polymer Electrolytes. Macromolecules 34(17):6052-6055. https://doi.org/ $10.1021 / \mathrm{ma} 0020032$

26. Cowie JMG, Spence GH (1999) Novel single ion, comb-branched polymer electrolytes. Solid State Ion 123(1):233-242. https://doi. org/10.1016/S0167-2738(99)00080-6

27. Akar E, Altınışık A, Seki Y (2012) Preparation of pH- and ionicstrength responsive biodegradable fumaric acid crosslinked carboxymethyl cellulose. Carbohyd Polym 90(4):1634-1641. https:// doi.org/10.1016/j.carbpol.2012.07.043

28. Lin X et al (2013) Synthesis, characterization and electrospinning of new thermoplastic carboxymethyl cellulose (TCMC). Chem Eng J vol. 215-216, pp 709-720. https://doi.org/10.1016/j.cej. 2012.10.089

29. Al-Gunaid MQA, Saeed AMN, Siddaramaiah (2018) Effects of the electrolyte content on the electrical permittivity, thermal stability, and optical dispersion of poly(vinyl alcohol)-cesium copper oxide-lithium perchlorate nanocomposite solid-polymer electrolytes. J Appl Polym Sci 135(8):45852. https://doi.org/10.1002/ app. 45852

30. Smith MJ, Silva MM, Cerqueira S, MacCallum JR (Apr. 2001) Preparation and characterization of a lithium ion conducting electrolyte based on poly(trimethylene carbonate). Solid State Ionics 140(3):345-351. https://doi.org/10.1016/S0167-2738(01)00815-3

31. Shafee EE (1996) Dielectric and conductivity relaxation in sodium carboxymethyl cellulose and its acid form. Carbohydr Polym 31(1):93-98. https://doi.org/10.1016/S0144-8617(96)00053-7 
32. Arya A, Sharma AL (2018) Effect of salt concentration on dielectric properties of Li-ion conducting blend polymer electrolytes. J Mater Sci: Mater Electron 29(20):17903-17920. https://doi.org/ 10.1007/s10854-018-9905-3

33. Winie T, Arof AK, Thomas S (2019) Polymer Electrolytes: Characterization Techniques and Energy Applications. John Wiley \& Sons

34. Funke K (1997) Ion transport in fast ion conductors - spectra and models. Solid State Ion 94(1):27-33. https://doi.org/10.1016/ S0167-2738(96)00500-0

35. Funke K (1988) Jump relaxation in solid ionic conductors. Solid State Ion vol. 28-30, pp 100-107. https://doi.org/10.1016/S01672738(88)80015-8

36. Hou WH, Chen CY, Wang CC, Huang YH (2003) The effect of different lithium salts on conductivity of comb-like polymer electrolyte with chelating functional group. Electrochimica Acta 48(6):679-690. https://doi.org/10.1016/S0013-4686(02) 00737-5

37. Stolwijk NA, Heddier C, Reschke M, Wiencierz M, Bokeloh J, Wilde G (2013) Salt-Concentration Dependence of the Glass Transition Temperature in PEO-NaI and PEO-LiTFSI Polymer Electrolytes. Macromolecules 46(21):8580-8588. https://doi.org/ $10.1021 / \mathrm{ma} 401686 \mathrm{r}$

38. Yue L et al (O2016) All solid-state polymer electrolytes for highperformance lithium ion batteries. Energy Storage Materials 5:139-164. https://doi.org/10.1016/j.ensm.2016.07.003

Publisher's Note Springer Nature remains neutral with regard to jurisdictional claims in published maps and institutional affiliations. 